\title{
Two experimental studies on the differential effects of low and high treatability information on the inclination to engage in cancer prevention
}

\author{
Yingqiu Wu ${ }^{1} \mathbb{D} \cdot$ Arie Dijkstra $^{1} \cdot$ Simon E. Dalley ${ }^{1}$
}

Accepted: 24 February 2022

(c) The Author(s) 2022

\begin{abstract}
Two 3(control versus LTI versus HTI) $\times 2$ (self-affirmation versus no self-affirmation)-experiments were conducted. The first study presented a news message on the treatability of bowel cancer $(\mathrm{N}=717)$; the second study was about skin cancer $(\mathrm{N}=342)$. The dependent variables were the intention to engage in preventive behaviors and message acceptance. The results showed that when participants were exposed to LTI, only when response efficacy was low, a self-affirmation procedure increased their intention to prevent cancer (experiment 1), and increased message acceptance (experiment 2). When participants were exposed to HTI, the self-affirmation procedure did not increase the intention, and even reduced message acceptance. The findings suggest that defensive processes were active in reaction to LTI, but not in reaction to HTI. Although publishing LTI and HTI information in the media serves legitimate goals, it may have positive but also negative unintended effects on preventive behaviors in the population.
\end{abstract}

Keywords Treatability information $\cdot$ Self-affirmation $\cdot$ Extended parallel process model $\cdot$ Bowel cancer $\cdot$ Skin cancer

Treatment-related information is one of the most pervasive forms of health information in the media (Adelman \& Verbrugge, 2000). Regarding cancer, treatment information has been found to be the most frequent cancer-related information in the news media such as newspapers, magazines, and televisions (Jensen et al., 2010; Slater et al., 2008). Treatability information refers to the information that demonstrates the degree to which the course of a disease can be changed by health professionals (Dawson et al., 2006; Wu et al., 2018). When the course of a disease can be positively changed by health professionals, the disease is regarded as "highly treatable". This high treatability information (HTI) is presented in the news media regularly, for example: "An effective cure for all types of cancer could be just five to 10 years away, according to one of the world's leading experts on the disease" (Johnston, 2017). On the contrary, when the course of a disease can hardly or not be changed, the disease is regarded as 'low treatable', and it can be found in the news

Yingqiu Wu

yingqiu.wu@rug.nl

1 Department of Social Psychology, University of Groningen, Groningen, the Netherlands media like: "For cancers diagnosed at that late of a stage, chemotherapy has been definitively shown to extend lifespan by only a few months at best" (Schultz, 2012). Considering the high association between cancer and death, and the high prevalence of cancer worldwide, treatability information regarding cancer is relevant for most people in the world (Bray et al., 2018; Siegel et al., 2020). Therefore, such information may easily influence people's perceived treatability of cancer, and their corresponding cancer preventive behaviors (e.g., Refaei et al., 2018). Indeed, previous research has found a relationship between treatability information and health behaviors (e.g., Howell \& Shepperd, 2013; van Kesteren et al., 2007). For example, people were less motivated to seek a diagnosis of disease after they were informed that the disease was lowly treatable (Dawson et al., 2006; Howell $\&$ Shepperd, 2013). Furthermore, some studies have found a positive association between high treatability and high intention to engage in cancer screenings (Refaei et al., 2018). Thus, treatability information is not inert; it is taken into account in health decisions, possibly with negative health effects.

One possible negative influence on health decisionmaking may concern the motivation to engage in preventive behavior. One example concerns the prevention of human 
immunodeficiency virus (HIV) infection: HIV-positive people reported lower motivation to have protective sexual behavior when they perceived HIV treatment as effective (van Kesteren et al., 2007). We approached the possible negative side effects of treatability information experimentally: Our past experiment found that exposure to a message which promised a high treatability of skin cancer in the future, lowered people's immediate intention to engage in the prevention of skin cancer (Wu et al., 2018). As treatability information is frequently communicated in media (e.g., Jensen et al., 2010; Slater et al., 2008), such influence on cancer prevention may be widespread in the population (Mazor et al., 2010). It is noteworthy that this issue of treatability information influencing preventive behaviors is only relevant: (1) for diseases whose occurrence is related to (preventive) health behaviors; (2) once they occurred, are perceived as treatable to a certain extent. To further understand the effects and to be able to prevent the potential negative effects of treatability information, the mechanism through which it produces negative effects on health behavior must be studied. Thus, the aim of this paper is to test to what extent self-regulatory defensive reactions (Ruttan \& Nordgren, 2016) are involved in the effects of LTI and HTI on intention to engage in cancer prevention.

The potential negative effects of treatability information on health behavior can be explained by the Extended Parallel Process Model (EPPM; Maloney et al., 2011; Witte, 1992). According to the EPPM, when the threat caused by incoming information is low, the motivation to engage in danger control (such as preventive action) is also low. When the threat is high, but still controllable by health behavior, people process the health information and carefully compare the benefits and the costs of health behavior, and they may engage in danger control. However, when the threat is high but cannot be controlled by health behavior, people process the health information defensively by avoiding, denying or reappraising the health information; they will engage in fear control. In the framework of the EPPM, treatability information influences the level of threat in the following ways.

On the one hand, HTI indicates that the disease is curable and that the consequences of cancer are less severe (Dawson et al., 2006), which weakens the threat of cancer to a controllable level. By cognitively analyzing the information, people may learn that cancer prevention is less urgent, and that the need to invest in prevention is not high. Because people tend to conserve their current resources (e.g., time, money, physical energy, psychological resources) for their most important values (Halbesleben et al., 2014; Hobfoll, 2011) - and most people have important values and plans in other domains than disease prevention - they may decide that prevention is of lesser importance. Thus, in the framework of EPPM, HTI reduces the necessity of danger control, possibly manifesting in a lower intention to engage in a specific preventive behavior. On the other hand, LTI indicates that the disease is not well curable and that the consequences of cancer are very severe (i.e., death), which strengthens the threat of cancer to an uncontrollable level. By handling the threat through defensively avoiding, denying or reappraising the information, people are able to eliminate the threat, at least when they perceive that the cancer is not easily prevented by behavior change. LTI increases the use of fear control so further reducing the use of danger control, possibly manifesting in a lower intention to engage in a specific prevention behavior. Thus, both LTI and HTI are expected to lower the inclination to engage in prevention behaviors, but for different reasons.

This study aimed to differentiate the two processes of LTI effects and HTI effects by experimentally applying a selfaffirmation procedure. Specifically, theories of self-affirmation suggest that by bolstering the important aspects of the selves, self-affirmation boosts inner resources and enables people to perform at an open-minded manner (e.g., Albalooshi et al., 2020; Cohen \& Sherman, 2014; Schmeichel \& Vohs, 2009). According to the theory of psychological reactance (Brehm, 1966; Reynolds-Tylus, 2019; Rosenberg \& Siegel, 2018; Schüz et al., 2013), when people are exposed to threatening health information such as LTI, their psychological reactance (i.e., the motivation of freedom restoration) is aroused as they feel that the information is trying to threaten, hinder, or eliminate their freedom to engage in unhealthy behaviors. As a result, people are more likely to show defensive reactions to the information, such as low message acceptance, or low intention to change. However, self-affirmation has been found to reduce such defensive reactions to threatening information (e.g., Reed \& Aspinwall, 1998; Sherman \& Cohen, 2006). While both HTI and LTI may lower the intention, we assume that self-affirmation will prevent the reduction in intention only in LTI, because only in LTI the low intention is caused by self-regulatory defenses (Albalooshi et al., 2020). This hypothesis is supported by the findings of Howell and Shepperd (2012) that in psychology students self-affirmation can reduce avoidance of personal-risk information only when a disease is untreatable. In the present study, we are particularly interested in treatability information on cancer, and the effects of it in a more general population.

The above effects of LTI and HTI are expected to occur especially in people who perceive specific preventive actions as no effective solution for lowering the threat. These people experience a higher baseline threat because they cannot influence their risk, they are "stuck". This individual difference perception is called low response efficacy: A low response efficacy indicates that people do not believe the threat can be changed by taking action, thereby leaving them stuck in the threat. In contrast, a high response efficacy means that people believe that by 
performing the cancer preventive behaviors, their high threat can be reduced (Lewis et al., 2010; Maloney et al., 2011). Thus, especially when response efficacy is low, LTI will lead to self-regulatory defenses that can be prevented with a self-affirmation condition. An earlier study ( $\mathrm{Wu}$ et al., 2018) indeed showed that the effects of HTI especially occurred when response-efficacy was low.

In sum, we predict that (1) self-affirmation will increase the intention to engage in cancer prevention in LTI conditions; (2) self-affirmation has no effects on the intention to engage in cancer prevention in HTI conditions; (3) the effects of self-affirmation and LTI/HTI on the intention to engage in cancer prevention will be found particularly under the condition of low response efficacy. Hence, two online experiments were conducted to examine our assumptions. Both of them employed a 3 (control versus low treatability versus high treatability) $\times 2$ (selfaffirmation versus no self-affirmation) design. The main dependent variable in both experiments was the intention to engage in cancer prevention, as intention remains the key psychological predictor of behavior, although there are discrepancies between intentions and behavior (Sheeran, 2002). There were some differences between the two experiments. In experiment 2, to test the occurrence of defensive self-regulation more directly, message acceptance was included as a dependent variable. In addition, the types of cancer the treatment information concerned differed between the experiments: We chose types of cancer that were highly prevalent, and: 1) were relevant for the general population (e.g., not only to smokers or females), and; 2) concerned distinct bodily systems to explore generalizability. Therefore, in experiment 1 the treatability information was about bowel cancer, in experiment 2 about skin cancer. Lastly, both experiments contained Dutch participants, but in experiment 1 also Chinese participants joined the study. Possible cultural differences in the effects of the manipulations will be explored.

\section{Experiment 1}

Experiment 1 examined how LTI and HTI influence the intention to engage in cancer prevention after being selfaffirmed. We predict that only after exposure to LTI, selfaffirmation will lead to an increase in intention. Besides, this pattern will especially occur when response efficacy is low. The experimentally manipulated LTI and HTI concerned the treatment of bowel cancer, and the intention to engage in prevention concerned lowering red meat and processed meat consumption, and increasing fruit and vegetable consumption.

\section{Method}

\section{Design and Manipulations}

This experiment employed a 3(control versus low treatability versus high treatability) $\times 2$ (self-affirmation versus no selfaffirmation) design. It was conducted online with the use of Qualtrics, an online survey system.

Self-Affirmation The manipulation of self-affirmation was based on the procedure of Allport et al.'s (1960) "study of values" (MCQueen \& Klein, 2006), and was validated in previous studies (e.g., Elbert \& Dijkstra, 2015). Participants were randomly assigned to the self-affirmation condition or the no self-affirmation condition. All were presented with a list of eight value domains (i.e., theory, economics, aesthetics, social aspects of life, politics, religion, environment, and hedonism). They were asked to select both, their most and their least valued domain. Then, they were asked to respond to ten dichotomous questions. In the self-affirmation condition, all ten questions included two options, and one option referred to the most important value of the participants, providing participants with opportunities to repeatedly choose the answer reflecting their most important value. In contrast, in the no-self-affirmation condition the ten questions contained options concerning the least important value of the participants, so they had no chance of reinstating the self by repeating their most important value (MCQueen \& Klein, 2006).

A pilot study including 47 student participants was conducted to check this particular self-affirmation procedure (Hauser et al., 2018). The participants were asked to answer five manipulation check questions (e.g., "These questions made me think about things personally important to me."). The results suggested that the manipulation of self-affirmation was successful, with a significantly higher score on the manipulation check in the self-affirmation condition than in the no self-affirmation condition $(p=.04)$.

Treatability Information The manipulations of the treatability information were embedded in an online news article constructed for this particular purpose. The earlier study (Wu et al., 2018) showed that the figures presented in the information effectively manipulated treatment success regarding a specific type of cancer. The high treatability information (HTI) was: "Within 20 years 90 percent of the bowel cancer patients can be cured", and the low treatability information (LTI) was: "Within 20 years 30 percent of the bowel cancer patients can be cured." In the control condition participants were asked to read a news article that was totally unrelated to human health. Besides, considering that the study was conducted in both Chinese and Dutch participants, the news articles were formulated in both languages, 
and formatted as a Chinese news website and a Dutch news website. Student assistants whose mother language is Chinese and Dutch finished the translations. Screenshots of the news articles in the different conditions can be found in Appendix 1.

\section{Recruitment and Procedure}

Participants were recruited from the general populations in China and in the Netherlands as the researchers have access to both populations and the experiment can be conducted using the national languages. The Dutch sample was recruited with a call on Facebook sites, and the Chinese sample was recruited with a call on famous Chinese social platforms such as QQ, Wechat and Weibo (Huang et al., 2013; Lien \& Cao, 2014; Zhang \& Pentina, 2012). The call mentioned that the study was about health information related to food and bowel cancer, and that participants were asked to read a news article and answer some questions about it. By clicking a link, they were routed to the online experiment. Firstly, we obtained informed consent from all participants, and the demographics were assessed. After this, the participants were provided with the definitions of red meat and processed meat, to prepare the subsequent assessment of meat consumption, which was also supported by pictures of portions of meat. Next, the World Health Organisation (WHO; 2015) recommendations on red and processed meat, and on fruit and vegetable consumption were presented. The WHO usually publishes the health guidelines that apply worldwide (Bayram \& Shields, 2021), including China and the Netherlands. The details of the partly illustrated information can be found in Appendix 2. Then participants were presented with several pre-test measures, after which they were randomly assigned to one of the six conditions, where they were instructed to read the experimental materials (the selections of values and the news article). Next, they were presented with the post-test measures, including the main outcome measures. At the end of the experiment, participants were debriefed by informing them that the article they just read was manipulated. In addition, the participants were suggested to find more actual information about bowel cancer through a link to a website. The complete version of the debrief messages can be found in Appendix 3.

\section{Measures}

Pre-Test Gender, age, and education level were assessed as demographic variables. Considering there are differences between Chinese and Dutch educational systems, we recoded the level of education into two levels: low and high. A low education indicates that the participants' highest education level is up to the secondary (more practical) education level. A high education level indicates that the participants' highest education level is at least the undergraduate education level. (family) History of bowel cancer was assessed by the measures adapted from the previous study (Wu et al., 2018) with three items: "Did you ever have bowel cancer yourself?"; "Was there ever bowel cancer in your first family line (parents, children, brothers or/and sisters)?"; "Was there ever bowel cancer in your second family line (grandparents, uncles or/and aunts)?" The items could be answered by Yes or No. These variables were recoded into "no (family) history" when all three questions were answered with "no," versus "a (family) history" when one or more questions were answered with "yes."

Perceived meat consumption was assessed with two items: "Do you think that in last months you ate too much $\mathrm{red} /$ processed meat?" The options were: I ate too much (6), I ate much (5), I didn't eat too much (4), I ate little (3), I ate very little (2), I didn't eat meat (1). The mean score was used as the scale score of perceived meat consumption. The correlation between the items was $r=.52, p<.001$.

The pre-test intention to engage in bowel cancer prevention was assessed using three items, adapted from a previous study (Elbert \& Dijkstra, 2015): "Are you planning to follow the recommendation of red meat consumption in the coming month?"; "Are you planning to follow the recommendation of processed meat consumption in the coming month?"; "Are you planning to follow the recommendation of vegetables and fruits consumption in the coming month?" The items could be answered on 5-point scales ranging from 1 (not planning at all) to 5 (certainly planning). The Cronbach's alpha was .80. The item scores were averaged to create a composite measure score of pre-test intention $(M=4.11, S D=1.79)$.

Participants' previous experiences regarding bowel cancer were measured by two items. Specifically, one item was used to measure participants' previous knowledge about bowel cancer: "How much do you know about bowel cancer?" This item could be answered on a scale of 1 (do not know anything) to 5 (know a lot). The other item was used to assess their previous protective behavior regarding bowel cancer: "Did you ever do anything to protect yourself from bowel cancer?" This item could be answered on a scale of 1 (nothing at all) to 5 (a lot).

Response efficacy regarding behaviors to prevent bowel cancer was assessed with the following three items: "Do you think that following the recommendation regarding read meat consumption is effective to avoid bowel cancer?"; "Do you think that following the recommendation regarding processed meat consumption is effective to avoid bowel cancer?"; and "Do you think that following the recommendation regarding fruit and vegetable consumption is effective to avoid bowel cancer?". The measures of response efficacy were adapted from an earlier study (Wu et al., 2018). These 
items could be answered on a 5-point scale, from 1 (not effective) to 5 (very effective). The Cronbach's alpha was 88.

Post-Test The main outcome measure was the intention to engage in bowel cancer preventive behavior, which was assessed with three items: "I am planning to eat a low level of red meat during the following month."; "I am planning to eat a low level of processed meat during the following month."; "I am planning to eat a sufficient level of vegetables and fruits during the following month.". These items were adapted from a previous study (Elbert \& Dijkstra, 2015). They could be answered on a scale of 1 (not planning at all) to 7 (planning very strongly). The Cronbach's alpha was .82 . The item scores were averaged to create a composite measure score of post-test intention $(M=5.50, S D=1.57)$.

Perceived treatability was measured as manipulation check. It was assessed with the following three items on 7-point scales: "How well can bowel cancer be treated?", to be answered from 1 (not very well treatable) to 7 (very well treatable); "How successful will the treatment of bowel cancer be in the future?", to be answered from 1 (not successful) to 7 (very successful); and "The treatability of bowel cancer will improve in the future.", to be answered from 1 (will not improve) to 7 (will strongly improve). The average item score was the perceived treatability score. The Cronbach's alpha was .82.

\section{Participants}

On the basis of our previous research, it was decided that at least 50 participants per condition would allow detection of a large effect (Cohen's $d>.90$ ) with .80 power (see Simmons et al., 2013). We chose to detect a large effect to enhance practical relevance of the outcomes. A total of 1150 participants entered the survey system, but 738 participants completed the measures. Four participants did not state their age, and 17 participants were younger than 18 years old; they were excluded from the final sample. This final sample $(N=717)$ consisted of $589(82.1 \%)$ female participants, $128(17.9 \%)$ male participants, and the age ranged from 18 to 70 years $(M=34.08, S D=10.43)$. Four hundred and fifteen participants provided data through the survey system in the Chinese language, while 302 participants provided data through the system in the Dutch language. Thirty-six percent of participants were classified as low educated, and the rest of them were classified as high educated. Eighty-two percent of the participants did not have a (family) history of bowel cancer (themselves or in their family). The mean score of participants' pre-test intention to take protective measures was $4.11(S D=1.08)$ on the 5-point scale, and the mean score on the self-reported meat consumption was 3.71
$(S D=1.12)$ on the 6-point scale (above "I ate little [meat]", and somewhat below "I didn't eat too much [meat]").

\section{Results}

\section{Randomization Check}

Chi-square test results revealed that the six conditions did not significantly differ on the pre-test variables "gender", "education level", "annual household income", "culture" and "(family) history of bowel cancer", all $p \mathrm{~s}>.34$. ANOVA test results revealed that the six conditions did not significantly differ on the variables "age", "knowledge about bowel cancer", "pre-test intention" and "self-reported meat consumption", $p s>.63$. Thus, the randomization seemed to have been successful.

\section{Manipulation Check}

To check whether the manipulations successfully affected perceived treatability, the six conditions were recoded into three conditions: low treatability, high treatability, and control. An ANOVA test showed that perceived treatability did not differ significantly between the three conditions, $F(2$, $714)=1.51, p=.22, \eta_{p}{ }^{2}=.04$. However, contrasts indicated that the perceived treatability in the low treatability conditions was significantly lower than in the high treatability condition (one-sided test $p<.05$ ). Thus, the LTI and HTI led to the expected differences in perceived treatability.

\section{Effects of Treatability Information, Self-Affirmation and Response Efficacy}

Because the expected effects were thought to occur especially when response efficacy was low, we firstly conducted a three-way interaction ANCOVA (treatability $\times$ self-affirmation $\times$ response efficacy) on the post-test intention to engage in bowel cancer prevention. We controlled for the effects of age, gender, culture, previous knowledge about bowel cancer, previous protective behavior, and pre-test intention as these variables were significantly related to the dependent variable (Mannocci, 2009), $p$ s <.01. This analysis revealed that the three-way interaction was significant, $F(2$, $699)=6.57, p=.001, \eta_{p}{ }^{2}=.018$. Within this saturated threeway model, there were no significant two-way interactions (all $p s>.26$ ).

Then, the effects of treatability and self-affirmation on post-test intention were tested separately for low and high response efficacy. The levels of response efficacy were modelled using the complete dataset, by decreasing and increasing the z-scores of response-efficacy with 1 standard deviation (Siero et al., 2009). Figure 1 shows the estimated means of post-test intention by treatability and self-affirmation on 
Fig. 1 Post-test intention to engage in bowel cancer prevention under six conditions, on two levels of response efficacy

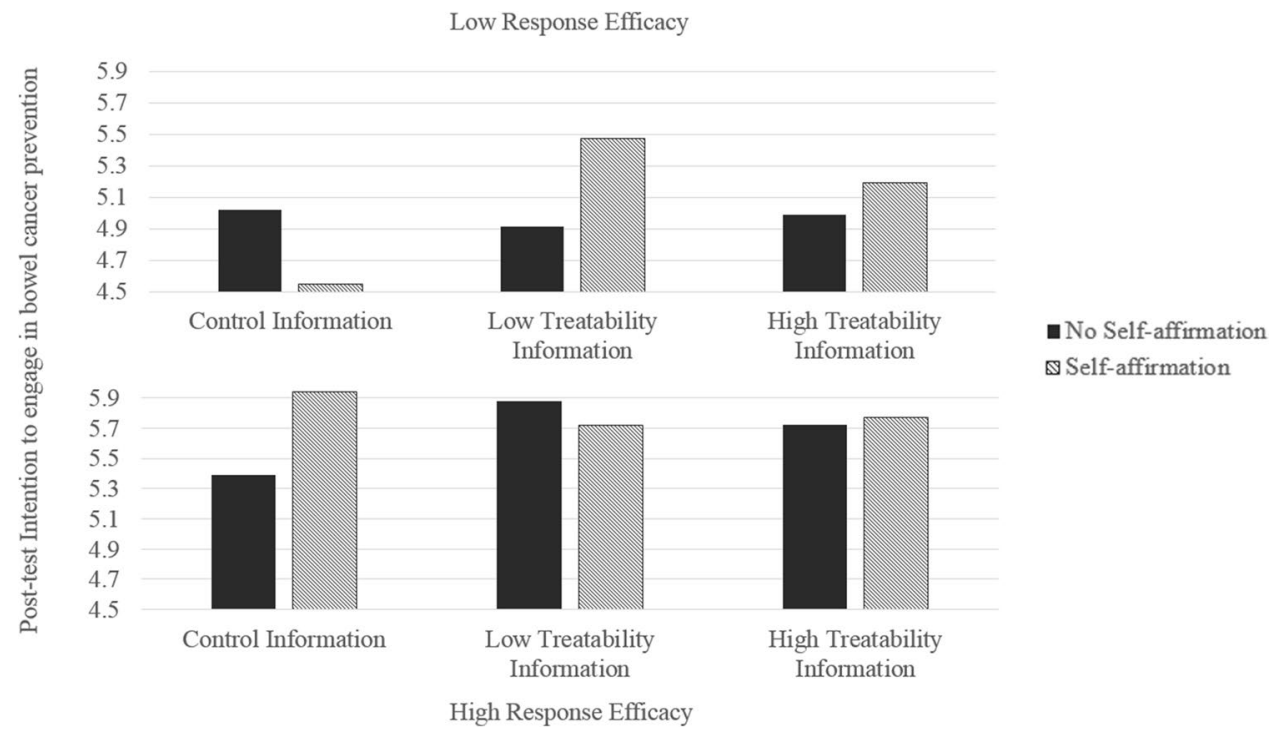

two levels of response efficacy. When response efficacy was low, there was a significant two-way interaction between treatability and self-affirmation, $F(2,699)=4.71, p<.01$, $\eta_{p}{ }^{2}=.013$. When response efficacy was high, this interaction was not significant $(p=.13)$. Contrast analyses when response efficacy was modelled as low, showed the expected effect of LTI and HTI: In the LTI condition, self-affirmation led to a significantly higher intention $(M=5.47)$ than no selfaffirmation $(M=4.91), p=.02$. This finding implies that initially the LTI led to a high threat that was down-regulated by self-regulatory defences, thereby lowering the intention. Self-affirmation prevented this by inducing open-mindedness. In the HTI condition there was no significant effect of self-affirmation, suggesting that there was no defensive self-regulation in the first place. Besides, when participants were affirmed, the LTI led to a significantly higher intention $(M=5.47)$ than HTI $(M=5.19), p=.03$, suggesting a higher threat from LTI compared to HTI.

In the control condition participant received no treatment information, only self-affirmation or not. A first observation is that the intention in LTI participants who were affirmed $(M=5.47)$, was also significantly higher than the intention of self-affirmed participants in the control condition $(M=4.55)$, $p<.01$. This may have multiple causes: On the one hand self-affirmation increased the intention by lowering the selfregulatory defences that were mobilized by the LTI. On the other hand, when participants did not receive treatment information (i.e., in the control condition), self-affirmation led to a lower intention $(M=4.55)$ compared to no self-affirmation $(M=5.02)$, although the difference only approached significance, $p=.05$.This suggests that self-affirmation is only beneficial to increase intention in combination with a threat message; self-affirmation-only may make people too confident to bother about prevention. At least, when their response-efficacy is low and, therefore, we assume that the threat (of cancer) is high.

When response efficacy was modelled as high, only one contrast was significant: Self-affirmation significantly increased the intention in the control group (from $M=5.39$ to $M=5.94), p=.03$, suggesting some defensive self-regulatory action even when people did not read a message about cancer, but only answered the survey questions about cancer.

A final observation is that, as shown in Figure 1, both LTI and HTI did not lower the intention compared to the control group, not when response efficacy was high and not when it was low, and not when participants were self-affirmed or not. This is of practical relevance as it means that this study does not show that treatability information has this negative side-effect as our earlier study showed.

Because the sample consisted of Dutch and Chinese participants, explorative analyses were conducted within the present research question. We started to check whether culture moderated the above three-way interaction; it did not, $F(2,688)=1.18, p=.31, \eta_{p}{ }^{2}=.003$, but in this saturated four-way interaction model, the above three-way interaction was still significant.

\section{Experiment 2}

Experiment 2 aimed to test our expectations and replicate the findings of experiment 1 but with two adaptations. Firstly, the type of cancer was changed. The experimentally manipulated LTI and HTI now concerned treatment for skin cancer, and the intention to engage in prevention concerned using sunblock, getting into the shade, and covering the skin (Wu et al., 2018). Secondly, although self-affirmation provides insight into the activity of 
self-regulatory defences, an additional measure was included to shed light on this: message acceptance. Low message acceptance indicates self-regulatory defensiveness (van Koningsbruggen et al., 2009). For instance, Liberman and Chaiken (1992) found that under the condition of high relevance, coffee drinkers believed less in the link between coffee consumption and a severe illness, which was presented in a persuasive message (see also Kunda, 1987). That is, these participants functionally rejected the message to lower their experienced threat. Accordingly, we expected that in LTI, participants' message acceptance will be increased after being self-affirmed. In HTI, however, the acceptance should be strong and not influenced by self-affirmation, as no self-regulatory defences are involved in HTI. Again, these effects are expected to especially occur when response efficacy is low.

\section{Method}

\section{Design and Manipulations}

This experiment also employed a 3 (control versus low treatability versus high treatability) $\times 2$ (self-affirmation versus no self-affirmation)-design. The self-affirmation manipulation was the same as in experiment 1, but the manipulations of treatability were formulated as follows: The high treatability information was: "Within 10 years 90 percent of the skin cancer patients can be cured (presently 20\% is cured)," and the low treatability information was: "Within 10 years 30 percent of the skin cancer patients can be cured (presently $20 \%$ is cured)." In both low and high treatability conditions, high susceptibility ("One in 4 Dutch people now gets skin cancer.") was induced to increase people's perceived threat of skin cancer. In the control condition participants were asked to read a news article on "watching the stars on a sunny evening", unrelated to human health. The screenshots of the online news articles in this experiment can be found in Appendix 4.

\section{Recruitment and Procedure}

Participants were recruited from the general Dutch population with a call on Facebook sites and online forums such as FOK!forum. The call indicated that the research was about health information of skin cancer, and that participants were asked to read a news article and answer some questions about it. The following procedure was identical to the one in experiment 1 . At the end of this experiment, the participants were also debriefed by the messages including accurate information, and the complete version of the debrief messages can be found in Appendix 5.

\section{Measures}

Pre-Test Most measures were adapted from our earlier study (Wu et al., 2018). At pre-test, gender, age and education level were assessed as demographic variables. The highest completed level of education could be rated as one of twelve different types of education, which were recoded into two levels: low and high. (family) History of skin cancer was assessed using the same format as in experiment 1 . One item assessed participants' knowledge about skin cancer, which was formulated as "How much do you know about skin cancer.' This item could be answered on a scale of 1 (too little) to 5 (too much).

The pre-test intention to take protective measures was assessed using two items: "When the temperature is 27 degrees or higher and the sun is shining, would you protect yourself from the sun in any way when you would go outside (e.g., cover your skin or use sun block)?"; "When the temperature is 17 degrees or higher and the sun is shining, would you protect yourself from the sun in any way when you would go outside (e.g., cover your skin or use sun block)?". These items could be answered on a scale of 1 (certainly not) to 5 (certainly). The correlation among the items was $.54(p<.001)$. The item scores were averaged to create a composite measure score of pre-test intention $(M=3.20, S D=1.03)$.

Self-reported sun block use was assessed with one item: "When I am in the sun, I use the sun block." This item could be answered on a 7-point scale, ranging from 1 (never), 2 (rarely), 3 (occasionally), 4 (regularly), 5 (often), 6 (very often), and 7 (always).

Response efficacy about skin cancer prevention behavior was assessed with the following three items: "It is useful to use sunblock to avoid sun burn and, thereby, skin cancer"; "It is useful to cover against the sun, for example by clothing, to avoid sun burn and, thereby, skin cancer"; and "It is useful to go into the shade or inside to avoid sun burn and, thereby, skin cancer". These items could be answered on a scale of 1 (certainly not) to 5 (very certain). The Cronbach's alpha was .70.

Post-Test There were two main outcome measures. The intention to engage in skin cancer prevention was assessed with five items: "When the temperature is 17 degrees or higher and the sun is shining, are you planning to protect yourself from the sun in any way when you would go outside (e.g., cover your skin or use sun block)?"; "When the temperature is 27 degrees or higher and the sun is shining, are you planning to protect yourself from the sun in any way when you would go outside (e.g., cover your skin or use sun block)?"; "I am planning to use sun block more often when the sun shines"; "I am planning to avoid the sun more often"; "I am planning to cover myself more often when 
the sun shines". These items were also used in the earlier study (Wu et al., 2018). The five items could be answered on 7-point scales ranging from 1 (not planning at all) to 7 (planning very strongly). The Cronbach's alpha was .84. The item scores were averaged to create a composite measure score of post-test intention $(M=4.60, S D=1.39)$.

The other main outcome measure was message acceptance, which was adapted from the study conducted by (Liberman \& Chaiken, 1992), and assessed with two items on 7-point scales: "Exposure to sunshine increases the risk of skin cancer", and "How important is it that people protect themselves from sunshine to avoid skin cancer." The first item assesses the belief in the central link between exposure and cancer, the second item assesses perceived importance of the behavior. It is assumed that a defensive reaction, meant to lower the perceived threat, will manifest as a lowered belief and lowered importance. This is the defensive form of cognitive reappraisal (Good \& Abraham, 2007). The correlation between the items was $.46(p<.001)$. The two item scores were averaged to create a composite measure score of message acceptance $(M=5.85, S D=.92)$.

Perceived treatability was assessed with three items in the same format as in experiment 1 but now concerning skin cancer. The average item score was the perceived treatability score, which was used as manipulation check. The Cronbach's alpha was .80 .

\section{Participants}

Similar as in the previous experiment, the sample size of at least 50 participants was decided to provide a satisfactory statistical power (Simmons et al., 2013). A total of 558 participants entered the survey system, but only 351 of them completed the measures. Because 9 participants were younger than 18 years old, they were excluded from the final sample. This final sample $(N=342)$ consisted of 295 (86.3\%) female participants, 47 (13.7\%) male participants, and the age ranged from 18 to 69 years $(M=28.35$, $\mathrm{SD}=10.91)$. Forty-two percent of participants were classified as low educated, and the rest of them were classified as high educated. Sixty-seven percent of the participants had no (family) history of skin cancer (themselves or in their family). The mean score of participants' knowledge about skin cancer was $3.08(S D=0.91)$. The mean score of participants' pre-test intention to take protective measures was $3.20(S D=1.03)$ on a 5-point scale, and the score on the self-reported sun block use was 4.69 $(S D=1.53)$ on the 7-point scale (between regularly and often).

\section{Results}

\section{Randomization Check}

Chi-Square test results revealed that the six conditions did not significantly differ on the pre-test variables "gender", "education level", and "(family) history of skin cancer", all $p s>.26$. ANOVA test results revealed that the six conditions did not significantly differ on the variables "age", "knowledge about skin cancer", "pre-test intention to take protective measures" and "self-reported sun block use", all $p s>.36$. Thus, the randomization seemed to be successful.

\section{Manipulation Check}

To check whether the manipulations successfully affected perceived treatability, the six conditions were recoded into three conditions: low treatability, high treatability, and a control condition. An ANOVA test showed that perceived treatability was significantly different among these three conditions, $F(2,339)=4.95, p=.01, \eta_{p}{ }^{2}=.03$. Contrasts indicated that the perceived treatability in the low treatability conditions $(M=5.13)$ was significantly lower than in the high treatability condition $(M=5.50 ; p=.006)$. The mean of the control condition fell in between $(M=5.47)$. Thus, the LTI and HTI led to the expected differences in perceived treatability.

\section{Effects on Message Acceptance}

The three-way interaction ANCOVA (treatability $\times$ selfaffirmation $\times$ response efficacy) was conducted, with message acceptance as the dependent variable. Age, pre-test protective behavior and pre-test intention were entered as covariates because they were all significantly associated with the dependent variable (Mannocci, 2009). The threeway interaction was significant, $F(2,327)=8.16, p<.001$, $\eta_{p}{ }^{2}=.048$. Within this three-way model, the two-way interaction between treatability and self-affirmation was also significant, $F(2,327)=6.71$., $p=.001, \eta_{p}{ }^{2}=.039$. To further understand the three-way interaction and test whether the expected effects would especially occur when response efficacy was low, subsequent analyses were conducted at two levels of response efficacy using the same strategy and analyses as used in experiment 1 (Siero et al., 2009).

Figure 2 shows the strength of message acceptance, by treatability and self-affirmation on two levels of response efficacy. When response efficacy was low, there was a significant two-way interaction between treatability and self-affirmation, $F(2,327)=12.86, p<.001, \eta_{p}{ }^{2}=.073$. When response efficacy was high, this interaction was not significant. Contrast analyses when response efficacy was modelled as low, showed the expected effect of LTI: In the 
Fig. 2 Message acceptance under six conditions, on two levels of response efficacy

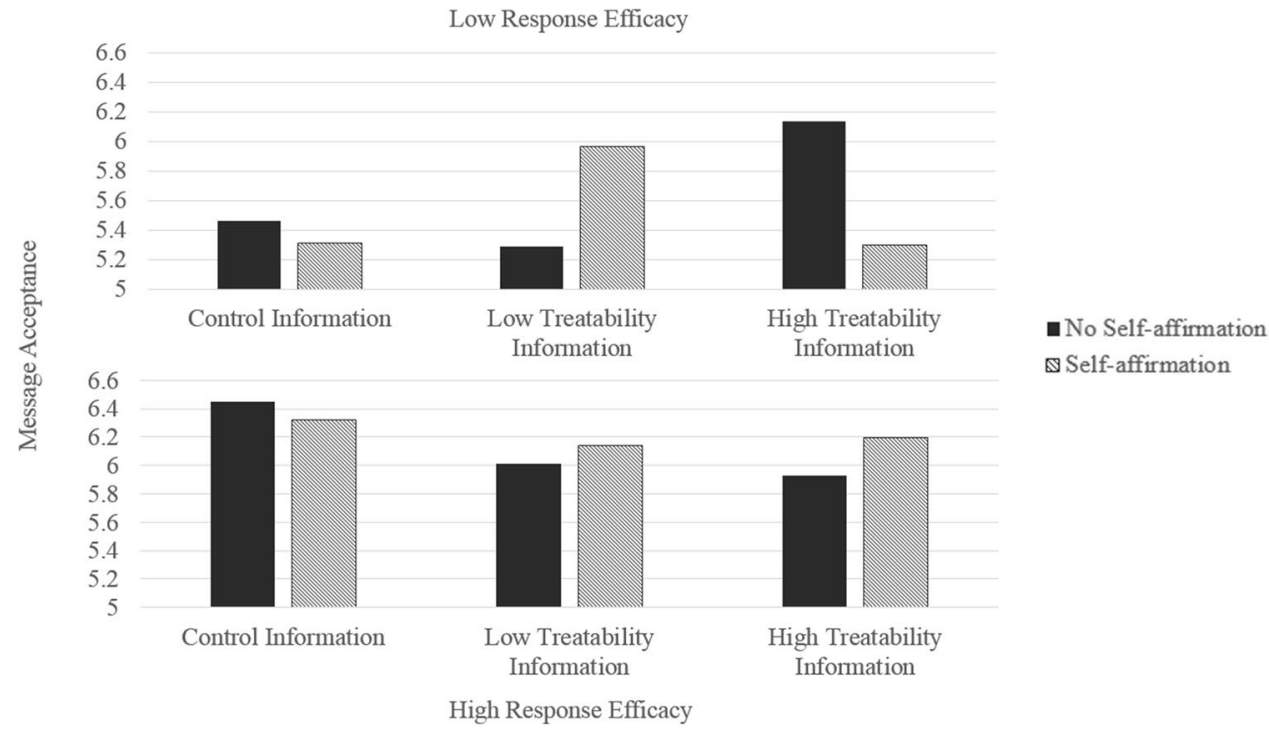

LTI condition, self-affirmation led to a significantly higher message acceptance $(M=5.97)$ than no self-affirmation $(M=5.28), p=.001$. In the HTI condition the effect of self-affirmation was the other way around: Self-affirmation led to a significantly lower message acceptance $(M=5.30)$ than no self-affirmation $(M=6.14), p<.001$.

Further analyses with response efficacy modelled as low were conducted concerning the control condition. Comparisons to the control condition showed that when participants were not self-affirmed, those in the HTI condition $(M=6.14)$ had a significantly stronger message acceptance than participants in the control condition $(M=5.47)$, $p=.003$. In contrast, when participants were self-affirmed, those in the LTI condition ( $M=5.97)$ had a significantly stronger message acceptance than participants in the control condition $(M=5.33), p=.004$. In addition, as can be seen in Figure 2, LTI and HTI did not lower message acceptance compared to the control condition. Thus, the analyses in low response efficacy showed no negative sideeffects of treatability information. This was different from when response efficacy was high: The only significant contrast showed that when people were not affirmed, the HTI significantly lowered message acceptance compared to the control condition, $F(1,325)=6.88, p=.009, \eta_{p}{ }^{2}=.021$. Thus, the optimistic HTI lowered the "spontaneous" level of acceptance.

To conclude, firstly, the effects were especially present in low response efficacy. Secondly, the effect of self-affirmation in LTI was expected but the effect of self-affirmation in HTI was not; the drop in message acceptance when HTI participants were affirmed was unanticipated, and may suggest that HTI is still a highly relevant type of information that can activate defensive self-regulation.

\section{Effects on Intention}

The three-way interaction ANCOVA (treatability $\times$ self-affirmation $\times$ response efficacy) was conducted, with the intention as the dependent variable, and the same covariates as above. This interaction was not significant, $F(2,325)=.212$, $p=.81, \eta_{p}{ }^{2}=.001$. To explore the data, we zoomed in on the simplest core of the experimental design: HTI versus LTI and self-affirmation versus no self-affirmation. The same pattern of means as with message acceptance was found: LTI and no self-affirmation $M=4.53$; LTI with self-affirmation $M=4.78$; HTI and no self-affirmation $M=4.73$; HTI with self-affirmation $M=4.42$. An ANCOVA showed that the HTI/LTI $\times$ self-affirmation/no self-affirmation interaction (so excluding the control condition) was significant, $F$ (1, $221)=4.05, p=.046, \eta_{p}{ }^{2}=.018$. Only one contrast was significant: When participants were self-affirmed, LTI led to a significantly higher intention than HTI, $F(1,121)=4.18$, $p=.04, \eta_{p}{ }^{2}=.033$. This latter contrast was also significant regarding intention in experiment 1 , and regarding message acceptance in experiment 2 , but in both cases only in people with low response-efficacy.

\section{Discussion}

Treatability information is regularly presented through media but it may have unintended effects on people's inclination to engage in cancer prevention. The two studies were conducted to demonstrate such effects, and to increase our understanding of the underlying mechanisms. The studies show several unintended effects that can influence prevention. 
In the case of LTI, as expected, self-affirmation successfully strengthened the intention to prevent bowel cancer in experiment 1 , especially when response efficacy was low. This finding is in line with several studies that induced a threat with persuasive health messages up to the level that people started to react defensively (van't Riet \& Ruiter, 2013). It suggests that the LTI, similar to persuasive health messages, induced a threat that made people adopt selfregulatory defenses that lowered their intention to engage in preventive behaviors. From the point of view of reactance theory (Brehm, 1966), they may reject the notion to engage in the behavior to protect or restore their freedom. Especially people with low response efficacy reacted defensively towards LTI (Lewis et al., 2010). In the EPPM, this is caused by fear and is conceptualized as fear control. The self-affirmation manipulation induced open-mindedness, thereby, "freeing" the threat into the solution to actually change behavior. This finding is not only meaningful in our theorizing but also suggests that our self-affirmation manipulation was valid and successful.

In experiment 2 the same pattern of means on intention was found after LTI but it was not significant. Besides intention, message acceptance was assessed. These results showed the same effect as in experiment 1: In the case of LTI self-affirmation led to a significant increase in acceptance, suggesting that without self-affirmation people rejected the message. Again, this suggests a defensive reaction towards the LTI. Although both experiments were conducted in different samples (one containing Chinese participants), and the LTI was about different types of cancers and different preventive behaviors, the results suggest the same psychological effects of LTI.

In the case of HTI, it was expected that the intention would be low initially and would not increase after selfaffirmation because the low intention was thought not to be caused by a defensive reaction (fear control) but by lowered threat (lowered danger control). In experiment 1, indeed, the intention after only HTI was low, as low as it was after LTI, and self-affirmation did not increase the intention. This is in line with our expectation that the quality or the cause of the low intention after HTI was different from the quality or cause of the intention after LTI. Exposure to HTI may make preventive actions look authentically less important: Because people are inclined to preserve resources, they lower their intention to invest in prevention (Hobfoll, 2011). In contrast, exposure to LTI may lead to an insufferable experience of threat that leads to immediate defensive actions, which is reflected in the low intention. Again, this was only in the case of low response efficacy; when people felt that engaging in prevention behaviors had little benefit to prevent bowel cancer. This experiment made clear that reactions towards HTI were essentially different from those towards LTI.
In experiment 2 with regard to skin cancer this was also the case with regard to message acceptance, when response efficacy was low. When participants were not affirmed, message acceptance after LTI was significantly lower than after HTI. Assuming that the low score after LTI indicates a defensive reaction, HTI seemed to make it easier to accept that "exposure to sunshine increases the risk of skin cancer", and the importance of people to "protect themselves from sunshine to avoid skin cancer." In comparison with LTI, HTI may have lowered the threat of cancer to such a level that people dared to face and accept the information. In the framework of the EPPM this might mean that HTI led to no, or to less fear compared to LTI. Secondly, self-affirmation significantly lowered message acceptance after HTI. Thus, affirmed participants now rejected the message more strongly. This suggests a (renewed) defensive reaction as we assume that a lowered message acceptance is in function of emotion-regulation (Liberman \& Chaiken, 1992; Sherman et al., 2000).

How can self-affirmation have this effect? The majority of self-affirmation studies show that self-affirmation increases intention and behavior (Epton et al., 2015; Sweeney \& Moyer, 2015), and this is thought to be caused by it inducing open-mindedness (van Koningsbruggen et al., 2009). However, there are also some other results published (MCQueen \& Klein, 2006). For example, Reed and Aspinwall (1998) found that self-affirmation, unexpectedly, significantly lowered the intention to engage in preventive behavior. Dijkstra (2014) showed in a single experimental design that self-affirmation could significantly increase the intention under some conditions but significantly decrease intention under different conditions. Thus, self-affirmation sometimes backfires. This might be explained by the notion that self-affirmation induces open-mindedness. The question then becomes, when will inducing open-mindedness backfire? This might be the case when emotion-regulation during the processing of threatening information is needed to face the information. We argue that when people process the information on a lethal and prevalent illness such as cancer, they always will regulate their emotions to a certain extent. When in this case self-affirmation induces open-mindedness, it may undermine this default emotion-regulation in such a way that the threat becomes too strong to face (Dijkstra, 2014); the emotion-regulation is "switched off". In such a case they need another way of coping with the threat, another emotion-regulation strategy. In line with this reasoning, emotion regulation research shows that people can choose from different emotion-regulation strategies (Sheppes et al., 2014; van't Riet \& Ruiter, 2013) for different levels of information intensity (Sheppes et al., 2011), and that strategies may fail (Koole, 2009). In the latter case, people may have to choose another strategy. 
The effects of self-affirmation preceding LTI (in low response efficacy) on intention in experiment 1 , and on message acceptance in experiment 2 , refer to the same underlying processes. In that, experiment 2 replicated experiment 1 conceptually. The differential findings regarding HTI are less easy to explain. The differences between experiment 1 and 2 on intention and message acceptance, respectively, may be confounded by the experiments presenting treatment information on different types of cancers, bowel and skin cancer, respectively. The found differences may be related to substantial differences in the levels of threat of the cancer types, and the related prevention behaviors. Thus, LTI showed the same pattern despite these differences, but the different effects of HTI may be caused by these differences.

The effects in the control condition also provide some relevant insights. People in the control condition did not read information on treatment, and this condition may reflect people's spontaneous starting position when they are exposed in natural settings to LTI or HTI in the media. In experiment 1 , when people with low response efficacy were affirmed, LTI led to a significant increase in intention, compared to the control condition. The same was the case in experiment 2 with regard to message acceptance: LTI increased their acceptance of the links between sunshine and cancer and between preventive action and cancer. As open-mindedness can be a normal psychological state in the population (Kang et al., 2017; Pietersma \& Dijkstra, 2011), this suggests that media messages on LTI can support preventive actions in a segment of the population. One negative side-effect of HTI was observed: When response efficacy was high, HTI led to a significant decrease in message acceptance, compared to participants in the control condition. This is in line with our earlier study which showed that HTI led to a lower intention compared to the control condition in participants with a family history of skin cancer (Wu et al., 2018).

Some relevant limitations must be acknowledged to get a realistic idea of the meaning of the findings. The dependent variables were intention to engage in preventive actions and message acceptance, not behavior. For ethical reasons we cannot use behavior as a dependent variable in a study with manipulations that can be expected to lower actual preventive behaviors. Such a study would demand a relevant follow-up period for new behavior to develop. During this period at least a part of the participants might lower their preventive behaviors and endanger themselves. Another limitation might be the differences in sample size and the resulting statistical power between both experiments. Particularly the fewer participants per condition in experiment 2 may have caused the null findings concerning intention as the dependent variable. Still, in both experiments the six conditions each contained more than the planned 50 participants. In addition, the effects of six conditions in low and in high response efficacy were not tested by a median split but by modelling the complete data set as low or high (Siero et al., 2009), thereby preserving statistical power. An additional limitation concerns the external validity of the present data: To what extent can the observed effect be found in the population? We did use a realistic news media format that looked real. However, some aspects of the experimental procedure may have lowered the generalizability. Firstly, the pre-test may have primed relevant memory nodes, which may have influenced their reactions towards the treatment information: Participants answered several questions about their perception and behavior related to cancer, and to provide them with a standard for answering the response efficacy questions, they were presented with the WHO recommendations for cancer prevention behaviors. In practice, this priming may not take place before people read treatment information. Because participants in the control condition were exposed to the same primes, this is especially an issue of external validity. Next, participants read the information only in one session, and then scored the dependent variables. In reality they may be exposed more often to such messages (Wu et al., 2018), which might lead to cumulative effects but also to habituation. Thus, care should be taken to translate the results in our experimental design directly to what happens in the population.

Nowadays people are exposed to many news messages about cancer that are meant to inform people or, often in the case of HTI, to motivate people to donate, or to raise hope for patients and their families. Although these goals are legitimate, LTI and HTI may have side-effects on prevention behaviors. LTI and HTI may unintendedly facilitate but also undermine society's broad efforts to prevent illnesses by behavior change. In designing strategies to prevent the latter undesired effects, it is important to observe that recipients with a high response efficacy - those who have a stronger belief that the prevention behaviors are indeed effective - scored higher on intention and on message acceptance, and displayed no defensive reactions. Thus, treatment information might always be accompanied by information that supports response efficacy, for example: "Although this is bad (LTI)/good (HTI) news, it is important to realize that engaging in prevention behavior X really lowers your risk to get cancer in the first place". Although this preliminary recommendation is plausible; in line with our results, and with theoretical notions on defensive reactions (Witte, 1992), its effectiveness should be studied. In general, the study of unintended effects of treatment information and other types of information on cancer through mass media is one important angle in cancer prevention that can save many lives.

Supplementary Information The online version contains supplementary material available at https://doi.org/10.1007/s12144-022-02952-z. 
Funding This research is supported by a grant from China Scholarship Council [grant number 201407720027].

Data Availability The datasets generated during and/or analysed during the current study are available from the corresponding author on reasonable request.

\section{Declarations}

Ethics Approval This research has been approved by Ethics Committee of Psychology at the University of Groningen [approval number 16033$\mathrm{O}]$. All procedures performed in studies involving human participants were in accordance with the ethical standards of the institutional and/ or national research committee and with the 1964 Helsinki declaration and its later amendments or comparable ethical standards.

Consent to participate Informed consent was obtained from all individual participants included in the study.

Conflict of Interest On behalf of all authors, the corresponding author states that there is no conflict of interest.

Open Access This article is licensed under a Creative Commons Attribution 4.0 International License, which permits use, sharing, adaptation, distribution and reproduction in any medium or format, as long as you give appropriate credit to the original author(s) and the source, provide a link to the Creative Commons licence, and indicate if changes were made. The images or other third party material in this article are included in the article's Creative Commons licence, unless indicated otherwise in a credit line to the material. If material is not included in the article's Creative Commons licence and your intended use is not permitted by statutory regulation or exceeds the permitted use, you will need to obtain permission directly from the copyright holder. To view a copy of this licence, visit http://creativecommons.org/licenses/by/4.0/.

\section{References}

Adelman, R. C., \& Verbrugge, L. M. (2000). Death makes news: The social impact of disease on newspaper coverage. Journal of Health and Social Behavior, 41(3), 347-367. https://doi.org/10.2307/ 2676325

Albalooshi, S., Moeini-Jazani, M., Fennis, B. M., \& Warlop, L. (2020). Reinstating the resourceful self: When and how self-affirmations improve executive performance of the powerless. Personality and Social Psychology Bulletin, 46(2), 189-203. https://doi.org/10. 1177/0146167219853840

Allport, G. W., Vernon, P. E., \& Lindzey, G. (1960). Study of values. In Manual: A scale for measuring the dominant interests in personality (3rd ed.). Houghton Mifflin.

Bayram, A. B., \& Shields, T. (2021). WHO trusts the WHO? Heuristics and Americans' Trust in the World Health Organization during the COVID-19 pandemic. Social Science Quarterly, 102(5), 2312-2330. https://doi.org/10.1111/SSQU.12977

Bray, F., Ferlay, J., Soerjomataram, I., Siegel, R. L., Torre, L. A., \& Jemal, A. (2018). Global cancer statistics 2018: GLOBOCAN estimates of incidence and mortality worldwide for 36 cancers in 185 countries. CA: a Cancer Journal for Clinicians, 68(6), 394-424. https://doi.org/10.3322/caac.21492

Brehm, J. W. (1966). A theory of psychological reactance. Academic Press.

Cohen, G. L., \& Sherman, D. K. (2014). The psychology of change: Self-affirmation and social psychological intervention. Annual
Review of Psychology, 65(1), 333-371. https://doi.org/10.1146/ annurev-psych-010213-115137

Dawson, E., Savitsky, K., \& Dunning, D. (2006). Don't tell me, I don't want to know': Understanding people's reluctance to obtain medical diagnostic information. Journal of Applied Social Psychology, 36(3), 751-768. https://doi.org/10.1111/j.0021-9029.2006. 00028.x

Dijkstra, A. (2014). The persuasive effects of personalization through: Name mentioning in a smoking cessation message. User Modeling and User-Adapted Interaction, 24(5), 393-411. https://doi.org/10. 1007/s11257-014-9147-x

Elbert, S. P., \& Dijkstra, A. (2015). Source reliability in auditory health persuasion: Its antecedents and consequences. Journal of Applied Biobehavioral Research, 20(4), 211-228. https://doi.org/10.1111/ jabr.12038

Epton, T., Harris, P. R., Kane, R., van Koningsbruggen, G. M., \& Sheeran, P. (2015). The impact of self-affirmation on healthbehavior change: A meta-analysis. Health Psychology, 34(3), 187-196. https://doi.org/10.1037/hea0000116sel

Good, A., \& Abraham, C. (2007). Measuring defensive responses to threatening messages: A meta-analysis of measures. Health Psychology Review, 1(2), 208-229. https://doi.org/10.1080/17437 190802280889

Halbesleben, J. R. B., Neveu, J.-P., Paustian-Underdahl, S. C., \& Westman, M. (2014). Getting to the "COR": Understanding the role of resources in conservation of resources theory. Journal of Management, 40(5), 1334-1364. https://doi.org/10.1177/0149206314 527130

Hauser, D. J., Ellsworth, P. C., \& Gonzalez, R. (2018). Are manipulation checks necessary? Frontiers in Psychology, 9(6), 998. https:// doi.org/10.3389/fpsyg.2018.00998

Hobfoll, S. E. (2011). Conservation of resources theory: Its implication for stress, health, and resilience. In S. Folkman (Ed.), The Oxford handbook of stress, health, and coping. Essay. Oxford University Press. https://doi.org/10.1093/oxfordhb/9780195375343.013.0007

Howell, J. L., \& Shepperd, J. A. (2012). Reducing information avoidance through affirmation. Psychological Science, 23(2), 141-145. https://doi.org/10.1177/0956797611424164

Howell, J. L., \& Shepperd, J. A. (2013). Reducing health-information avoidance through contemplation. Psychological Science, 24(9), 1696-1703. https://doi.org/10.1177/0956797613478616

Huang, R., Kim, H., \& Kim, J. (2013). Social capital in QQ China: Impacts on virtual engagement of information seeking, interaction sharing, knowledge creating, and purchasing intention. Journal of Marketing Management, 29(3-4), 292-316.

Jensen, J. D., Moriarty, C. M., Hurley, R. J., \& Stryker, J. E. (2010). Making sense of Cancer news coverage trends: A comparison of three comprehensive content analyses. Journal of Health Communication, 15(2), 136-151. https://doi.org/10.1080/1081073090 3528025

Johnston, I. (2017). Cure for cancer 'is coming within the next 10 years'. The Independent. http://www.independent.co.uk/life-style/ health-and-families/health-news/world-cancer-day-2017-effectivecure-will-happen-five-to-10-years-expert-karol-sikora-a7558846. html.

Schultz, D. (2012). Many Terminal Cancer Patients Mistakenly Believe A Cure Is Possible. NPR. https://www.npr.org/sections/healthshots/2012/10/24/163572138/many-terminal-cancer-patientsmistakenly-believe-a-cure-is-possible

Kang, Y., O'Donnell, M. B., Strecher, V. J., \& Falk, E. B. (2017). Dispositional mindfulness predicts adaptive affective responses to health messages and increased exercise motivation. Mindfulness, 8(2), 387-397. https://doi.org/10.1007/s12671-016-0608-7

Koole, S. L. (2009). The psychology of emotion regulation: An integrative review. Cognition and Emotion, 23(1), 4-41. https://doi.org/ $10.1080 / 02699930802619031$ 
Kunda, Z. (1987). Motivated inference: Self-serving generation and evaluation of causal theories. Journal of Personality and Social Psychology, 53(4), 636-647. https://doi.org/10.1037/0022-3514.53.4.636

Lewis, I. M., Watson, B., \& White, K. M. (2010). Response efficacy: The key to minimizing rejection and maximizing acceptance of emotion-based anti-speeding messages. Accident Analysis \& Prevention, 42(2), 459-467. https://doi.org/10.1016/j.aap.2009.09. 008

Liberman, A., \& Chaiken, S. (1992). Defensive processing of personally relevant health messages. Personality and Social Psychology Bulletin, 18(6), 669-679. https://doi.org/10.1177/0146167292 186002

Lien, C. H., \& Cao, Y. (2014). Examining WeChat users' motivations, trust, attitudes, and positive word-of-mouth: Evidence from China. Computers in Human Behavior, 41, 104-111. https://doi. org/10.1016/j.chb.2014.08.013

Maloney, E. K., Lapinski, M. K., \& Witte, K. (2011). Fear appeals and persuasion: A review and update of the extended parallel process model. Social and Personality Psychology Compass, 5(4), 206-219. https://doi.org/10.1111/j.1751-9004.2011.00341.x

Mannocci, A. (2009). The Mantel-Haenszel procedure. 50 years of the statistical method for confounders control. Italian Journal of Public Health, 6(4). https://doi.org/10.2427/5765

Mazor, K. M., Calvi, J., Cowan, R., Costanza, M. E., Han, P. K., Greene, S. M., Saccoccio, L., Cove, E., Roblin, D., \& Williams, A. (2010). Media messages about cancer: What do people understand? Journal of Health Communication, 15(Suppl 2), 126-145. https://doi.org/10.1080/10810730.2010.499983

McQueen, A., \& Klein, W. M. P. (2006). Experimental manipulations of self-affirmation: A systematic review. Self and Identity, 5(4), 289-354. https://doi.org/10.1080/15298860600805325

Pietersma, S., \& Dijkstra, A. (2011). Do behavioral health intentions engender health behavior change? A study on the moderating role of self-affirmation on actual fruit intake versus vegetable intake. British Journal of Health Psychology, 16(4), 815-827. https://doi. org/10.1111/j.2044-8287.2011.02018.x

Reed, M. B., \& Aspinwall, L. G. (1998). Self-affirmation reduces biased processing of health-risk information. Motivation and Emotion, 22(2), 99-132. https://doi.org/10.1023/A:1021463221 281

Refaei, M., Dehghan Nayeri, N., Khakbazan, Z., Yazdkhasti, M., \& Shayan, A. (2018). Exploring effective contextual factors for regular cervical Cancer screening in Iranian women: A qualitative study. Asian Pacific journal of cancer prevention: APJCP, 19(2), 533-539. https://doi.org/10.22034/APJCP.2018.19.2.533

Reynolds-Tylus, T. (2019). Psychological reactance and persuasive health communication: A review of the literature. Frontiers in Communication, 56. https://doi.org/10.3389/fcomm.2019. 00056

Rosenberg, B. D., \& Siegel, J. T. (2018). A 50-year review of psychological reactance theory: Do not read this article. Motivation Science, 4(4), 281-300. https://doi.org/10.1037/mot0000091

Ruttan, R. L., \& Nordgren, L. F. (2016). The strength to face the facts: Self-regulation defends against defensive information processing. Organizational Behavior and Human Decision Processes, 137, 86-98. https://doi.org/10.1016/j.obhdp.2016.06.006

Schmeichel, B. J., \& Vohs, K. (2009). Self-affirmation and self-control: Affirming core values counteracts ego depletion. Journal of Personality and Social Psychology, 96(4), 770-782. https://doi.org/ $10.1037 / \mathrm{a} 0014635$

Schüz, N., Schüz, B., \& Eid, M. (2013). When risk communication backfires: Randomized controlled trial on self-affirmation and reactance to personalized risk feedback in high-risk individuals. Health Psychology, 32(5), 561-570. https://doi.org/10.1037/a0029887
Sheeran, P. (2002). Intention-Behavior relations: A conceptual and empirical review. European Review of Social Psychology, 12(1), 1-36. https://doi.org/10.1080/14792772143000003

Sheppes, G., Scheibe, S., Suri, G., \& Gross, J. J. (2011). Emotionregulation choice. Psychological Science, 22(11), 1391-1396. https://doi.org/10.1177/0956797611418350

Sheppes, G., Scheibe, S., Suri, G., Radu, P., Blechert, J., \& Gross, J. J. (2014). Emotion regulation choice: A conceptual framework and supporting evidence. Journal of Experimental Psychology: General, 143(1), 163-181. https://doi.org/10.1037/a0030831

Sherman, D. A. K., \& Cohen, G. L. (2006). The psychology of selfdefense: Self-Affirmation theory Academic Press. https://doi.org/ 10.1016/S0065-2601(06)38004-5.

Sherman, D. A. K., Nelson, L. D., \& Steele, C. M. (2000). Do messages about health risks threaten the self? Increasing the acceptance of threatening health messages via self-affirmation. Personality and Social Psychology Bulletin, 26(9), 1046-1058. https://doi.org/10. 1177/01461672002611003

Siegel, R. L., Miller, K. D., \& Jemal, A. (2020). Cancer statistics, 2020. CA: a Cancer Journal for Clinicians, 70(1), 7-30. https://doi.org/ $10.3322 /$ caac. 21590

Siero, F. W., Huisman, M., \& Kiers, H. A. (2009). Analyse van moderatoreffecten 18. Voortgezette regressie-en variantieanalyse, 139-169.

Simmons, J. P., Nelson, L. D., \& Simonsohn, U. (2013). Life after P-Hacking. SSRN Electronic Journal. https://doi.org/10.2139/ ssrn.2205186

Slater, M. D., Long, M., Bettinghaus, E. P., \& Reineke, J. B. (2008). News coverage of cancer in the U.S.: A national sample of newspapers, television and magazines. Journal of Health Communication, 13(6), 523-537. https://doi.org/10.1080/10810730802279571

Sweeney, A. M., \& Moyer, A. (2015). Self-affirmation and responses to health messages: A meta-analysis on intentions and behavior. Health Psychology, 34(2), 149-159. https://doi.org/10.1037/hea00 00110

van't Riet, J., \& Ruiter, R. A. C. (2013). Defensive reactions to healthpromoting information: An overview and implications for future research. Health Psychology Review, 7, S104-S136. https://doi. org/10.1080/17437199.2011.606782

van Kesteren, N. M. C., Hospers, H. J., \& Kok, G. (2007). Sexual risk behavior among HIV-positive men who have sex with men: A literature review. Patient Education and Counseling, 65(1), 5-20. https://doi.org/10.1016/j.pec.2006.09.003

van Koningsbruggen, G. M., Das, E., \& Roskos-Ewoldsen, D. (2009). How self-affirmation reduces defensive processing of threatening health information: Evidence at the implicit level. Health Psychology, 28(5), 563-568. https://doi.org/10.1037/a0015610

Witte, K. (1992). Putting the fear back into fear appeals: The extended parallel process model. Communication Monographs, 59(4), 329_ 349. https://doi.org/10.1080/03637759209376276

World Health Organization. (2015). Cancer: Carcinogenicity of the consumption of red meat and processed meat. https://www.who. $\mathrm{int} /$ news-room/questions-and-answers/item/cancer-carcinogen icity-of-the-consumption-of-red-meat-and-processed-meat

Wu, Y., Dijkstra, A., Dalley, S. E., \& Roerink, F. S. (2018). An experimental test to reveal negative side-effects of high treatability information on preventative health behavior. Psychology \& Health, 33(8), 1028-1048. https://doi.org/10.1080/08870446.2018.1456290

Zhang, L., \& Pentina, I. (2012). Motivations and usage patterns of Weibo. Cyberpsychology, Behavior and Social Networking, 15(6), 312-317. https://doi.org/10.1089/cyber.2011.0615

Publisher's Note Springer Nature remains neutral with regard to jurisdictional claims in published maps and institutional affiliations. 